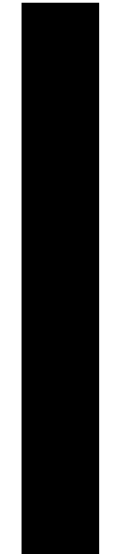

\title{
The Effect of Microwave Disinfection on the Dimensional Change of Acrylic
}

Resins.

\author{
Ahmad M Hussen \\ BDS, MSc (Assist Lect) \\ Lamia T Rejab \\ BDS, MSc (Lect) \\ Luay N Abbood \\ BDS, MSc (Assist Lect)
}

\author{
Dept of Prosthetic Dentistry \\ College of Dentistry, University of Mosul
}

Aims: To evaluate the effect of the microwave disinfection on the dimensional changes of the heatcured acrylic resin. Materials and Methods: Heat-cured acrylic resin was used in this study. Thirty two disk-shaped specimens with reference points were prepared to evaluate the linear dimensional changes of the heat-cured acrylic resin that sterilized by microwave irradiation and by chemical solutions chlorhexidine and sodium hypochlorite. The specimens were divided into four tested groups, eight specimens for each group. Group I as control group and other groups divided according to the sterilization method. The dimensional change was evaluated with an Electronic Digital Caliper. Mean values wear compared statistically with: One-way Analysis of Variance (ANOVA), followed by Duncan's Multiple Range Test to determine the significant different among the tested groups at $(p \leq 0.05)$ level of significance. Results: They showed that there was a highly significant difference of the means values of the linear dimensional change among the four tested groups. Specimens sterilized by microwave irradiation have a higher value than that sterilized by the chemical solutions. Conclusions: The results of this study appeared that sterilization by the microwave irradiation produce a significant effect on the dimensional stability of the heat-cured acrylic resin, while sterilization by chemical solution produce no significant difference.

Key words: Dimensional change, heat-cured acrylic resin, sterilization, microwave irradiation.

Hussen AM, Rejab LT, Abbood LN. The Effect of Microwave Disinfection on the Dimensional Change of Acrylic Resins. Al-Rafidain Dent J. 2008; 8(1 ): 38-43.

Received: 19/2/2007

Sent to Referees: $19 / 2 / 2007$

Accepted for Publication: 24/4/2007

\section{INTRODUCTION}

Heat-cured acrylic resins polymethyl methacrylate (PMMA) are widely used materials for the construction of many dental prostheses such as jacket crowns, veneers for cast gold restorations, temporary crown and bridge, complete denture, and removable partial dentures ${ }^{(1,2)}$.

Dental prostheses used by patients are exposed to normal oral microbial flora to include bacteria, viruses, and fungi. Dental personnel adjusting or repairing these prostheses may therefore be at risk of contracting infections from prostheses that have not been properly disinfected ${ }^{(3,4)}$. Considerations to eliminate cross contamination between the dental operator and the dental laboratory requires that dental prostheses be disinfected before sending to the laboratory and before delivery to the Patient ${ }^{(5)}$. Therefore, improved barrier techniques in handling dental prostheses are necessary to protect dental personnel and patients from bacterial and viral infection that can be transmitted through procedures associated with dental care. Sterilization and disinfection have become popular and widely used methods for eradicating microorganisms from the surface of prostheses and controlling cross contamination ${ }^{(6)}$.

Immersion and spray disinfection as well as various disinfection solutions have been tested and proven to be effective for this purpose ${ }^{(7)}$. Certain combinations of methods / disinfectant are more effective than others. It is important to weigh the effectiveness of the method / disinfectant used against the possible negative side effects on the material. Of particular importance are the dimensional accuracy and surface detail ${ }^{(8)}$.

Chemical disinfectant solutions recommended for immersion of dental prostheses include: Sodium hypochlorite, glutar- 
aldehyde, chlorine dioxide and chlorhexidine ${ }^{(4,6)}$.

Clorhexidine is potent topical antiseptic effective in high dilutions against a wide range of both: Gram-positive, gramnegative bacteria, yeast, fungi, facultative anaerobes and aerobes organisms. One of the most important disadvantages of such solution is the brownish discoloration of the teeth, tongue, plastic restoration, and even the acrylic denture base ${ }^{(6,9)}$.

Sodium hypochlorite is an effective wide spectrum disinfectant and can be used for routine disinfection of contaminated surfaces, but its effectiveness is reduced in the presence of an organic material like a blood. The major disadvantage of sodium hypochlorite is that having a moderating offensive odder due to the release of gaseous chlorine ${ }^{(10,11)}$.

It has been shown that some disinfecttant solutions caused changes in the physical and mechanical properties of denture base resins. It is likely that certain components of the disinfectant solutions may penetrate the material and not be completely eliminated by rinsing. These components may be unintentionally introduced into the oral cavity. In addition, the use of disinfectants has been considered to be time consuming or inappropriate. If the prostheses is heavily contaminated, it may not be completely disinfected by immersion alone ${ }^{(6)}$.

The use of microwave irradiation to disinfect dentures has recently been suggested. Studies have demonstrated that the effectiveness of microwave disinfection in deactivating potentially pathogenic microorganisms, such as: Staphylococcus aureus, Pseudomonas aeruginosa, Bacillus subtilis, and Candida albicans, was improved when the specimens were irradiated while immersed in water ${ }^{(6,12,13)}$.

The aims of this study is to evaluate the effect of the microwave disinfection on the dimensional changes of the heat-cured acrylic resin and compared with immerseon in chemical disinfectant solutions (chlorhexidine and sodium hypochlorite).

\section{MATERIALS AND METHODS}

Heat-cured acrylic resin Major (Major prodotti, Italy) was used in this study. Aluminum discs, $50 \mathrm{~mm}$ in diameter and $0.5 \mathrm{~mm}$ in thickness with reference points $\mathrm{A}, \mathrm{B}, \mathrm{C}$, and D was used to fabricate the specimens ${ }^{(14)}$. Measurements were made across each dimension ( $\mathrm{AB}$ and $\mathrm{CD}$ ) directly from the aluminum discs with an Electronic Digital Caliper( ISO-USA) to the nearest $0.01 \mathrm{~mm}$. From these measurements, a baseline measurement was calculateed. These measurements were made by a single calibrated operator.

Aluminum discs invested in standard two parts dental flasks in a manner similar to that used in conventional denture construction as shown in Figure (1).

The heat-cured acrylic resin was mixed at powder / liquid ratio according to the manufacturer's instruction. Specimens cured with the conventional denture flasking procedure. The specimens processed at polymerization cycle of 9 hours at $71^{\circ} \mathrm{C}$ in a thermostatically controlled water bath ${ }^{(6)}$. Specimens were divided into four groups depending on the sterilization methods. Group I (control): specimens were immersed in distilled water for 7 days. Group II: specimens immersed in $(0.2 \%)$ clorhexidine solution at room temperature $\left(21^{\circ}\right.$ $\mathrm{C} \pm 1$ ), the time recommended for disinfecting about (30) minutes ${ }^{(15)}$, then immersed in distilled water. This procedure repeated every day for 7 days. Group III: specimens immersed in $(0.05 \%)$ sodium hypochlorite solution at room temperature ( $21^{\circ} \mathrm{C} \pm 1$ ), the time recommended for disinfecting about $(10)$ minutes ${ }^{(11,15)}$, then immersed in distilled water. Also this procedure repeated every day for 7 days. Group IV specimens were sterilized by microwave energy, the specimens were individually placed in a 200-ml beaker of distilled water at room temperature $\left(21^{\circ}\right.$ $\mathrm{C} \pm 1$ ) in the microwave oven (Samsung, Model RE-570 D, 0.6 cuft, Korea) and subjected to microwave sterilization at 650 $\mathrm{W}$ for 6 minutes, then also immersed in distilled water ${ }^{(6)}$, the procedure repeated every day for 7 days. Water temperature that used during microwave sterilization was measured after sterilization by a digital thermometer (MY-14, CHINA), it was $\left(71^{\circ} \mathrm{C}\right)$. Eight specimens for each group were prepared, so the final total number was thirty two.

\section{Measurement of linear dimensional changes: \\ Poly methyl methacrylate (PMMA)} undergo unavoidable dimensional changes during fabrication, such as thermal expansion on heating, contraction on cooling, 
and polymerization contraction ${ }^{(16)}$. Linear shrinkage has been reported to be $0.2-0.9$ $\%$ for commercial acrylic resins ${ }^{(17)}$. So in respect to this changes and to exclude such dimensional changes that may result during specimens preparation, measurements were made on all specimens after specimens preparation and after treated in four tested groups.

The symmetrically located index mar-ks of the aluminum discs, which were reproduced by the specimens, facilitated the direct comparison of the linear dimension change in each of the specimens, Figure (1). The difference between the

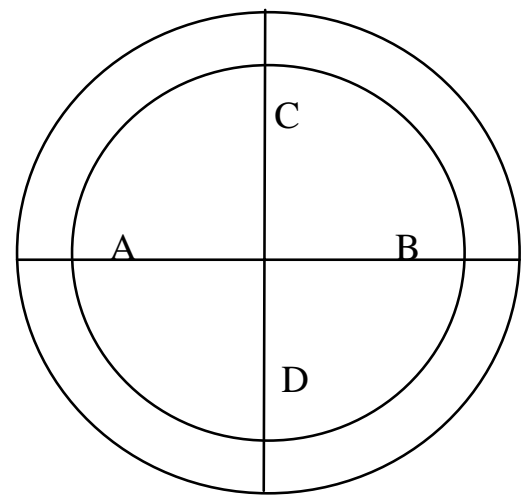

Figure (1): Aluminum disk flaking and acrylic resin specimen measurement with digital caliper

\section{RESULTS AND DISCUSSION}

The means of the linear dimensional changes were shown in Table (1). Results of ANOVA of this study were listed in Tables (2-5). The result of ANOVA in Table (2) showed that there was highly significant difference for the linear dimensional changes among the four tested groups, it means that the methods of the sterilization have a different effect on the dimensional stability of the acrylic resins and cause dimensional changes.

The results of ANOVA in Tables (3 and 4) showed there was no significant difference between Group I (control gro-up) specimens immersed in distilled wat-er, and Group II specimens that sterilized by immersion in $(0.2 \%)$ clorhexidine solution, also with Group III specimens dimensions across each ( $\mathrm{AB}$ and $\mathrm{CD}$ ) dimension of each specimen before and after sterilization was calculated as a linear dimensional changes. Measurements were made on all specimens by the same investtigator. Six measurements were made across each line for each specimen.

Statistically, mean values and standard deviation wear calculated. The resulting data were subjected to One-way Analysis of Variance. Duncan's Multiple Range test, was used to determine the significant different among the groups at $(p \leq 0.05)$ level of significance.

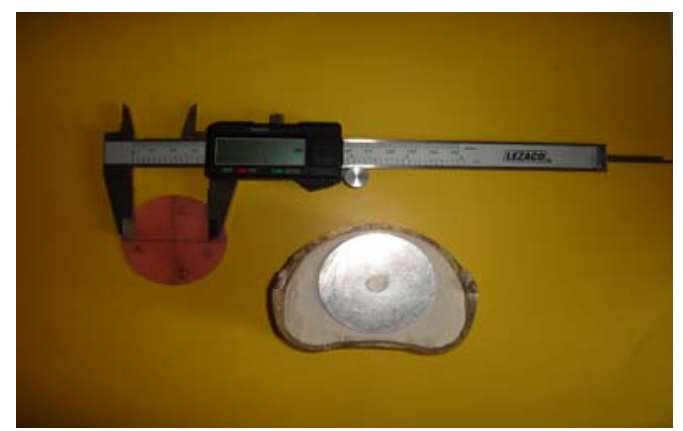

sterilized by immersion in (0.05 \%) sodium hypochlorite solution. While the results of ANOVA in Table (5) showed highly significant difference between Group I, and Group IV specimens which sterilized by microwave irradiation method. The results of Duncan's Multiple Range test in Table (6) showed sterilization by microwave method Group IV had the greatest effect and cause linear dimensional changes ( $0.35 \mathrm{~mm}$ ), then followed by Group III with less effect (0.2 $\mathrm{mm}$ ) linear dimensional changes, while Group II cause $(0.18 \mathrm{~mm})$ linear dimensional changes which had less effect than effect of Group III and Group IV. Group I had the least effect and cause $(0.1 \mathrm{~mm})$ linear dimensional changes. 
Table (1): Means of the linear dimensional changes (mm) of the tested groups.

\begin{tabular}{ccc}
\hline Tested groups & Number & Mean \\
\hline Group I & 8 & 0.1 \\
Group II & 8 & 0.18 \\
Group III & 8 & 0.2 \\
Group IV & 8 & 0.35 \\
\hline
\end{tabular}

Group I: specimens immersed in distilled water (controlled group); Group II: specimens immersion in (0.2 \%) chlorhexidine solution; Group III: specimens immersion in (0.05 \%) sodium hypochlorite solution; Group IV: specimens sterilized by microwave irradiation.

Table ( 2 ): ANOVA for the means of the of linear dimensional changes ( $\mathrm{mm}$ ) of the tested groups.

\begin{tabular}{cccccc}
\hline \multirow{2}{*}{ S.O.V } & \multirow{2}{*}{ DF } & \multicolumn{4}{c}{ Linear dimensional changes $(\mathbf{m m})$} \\
\cline { 3 - 6 } & & SS & MS & F & $* \mathbf{P} \leq \mathbf{0 . 0 1}$ \\
\hline Tested groups & 3 & 0.2614 & 0.0871 & 8.09 & 0.000 \\
Error & 28 & 0.3014 & 0.0108 & & \\
Total & 31 & 0.3528 & & & \\
\hline
\end{tabular}

* Mean: Highly significant; DF: Degree of freedom; SS: Sum of squares; MS: Mean of squares.

Table (3): ANOVA for the means of the of Linear dimensional Changes (mm) of the Group I and Group II.

\begin{tabular}{cccccc}
\hline \multirow{2}{*}{ S.O.V } & \multirow{2}{*}{ DF } & \multicolumn{4}{c}{ Linear dimensional changes of $(\mathbf{m m})$} \\
\cline { 3 - 6 } & & SS & MS & F & $* \mathbf{P} \leq \mathbf{0 . 0 1}$ \\
\hline Tested groups & 1 & 0.0256 & 0.0256 & 2.73 & 0.121 \\
Error & 14 & 0.1314 & 0.00939 & & \\
Total & 15 & 0.1570 & & & \\
\hline
\end{tabular}

* Means are not significant; DF: Degree of freedom; MS: Mean of squares.

Table ( 4 ): ANOVA for the means of the of linear dimensional changes (mm) of the Group I and Group III.

\begin{tabular}{cccccc}
\hline \multirow{2}{*}{ S.O.V } & \multirow{2}{*}{ DF } & \multicolumn{4}{c}{ Linear dimensional changes of (mm) } \\
\cline { 3 - 6 } & & SS & MS & F & $* \mathbf{P} \leq \mathbf{0 . 0 1}$ \\
\hline Tested groups & 1 & 0.04 & 0.0400 & 3.11 & 0.1 \\
Error & 14 & 0.18 & 0.0129 & & \\
Total & 15 & 0.22 & & & \\
\hline
\end{tabular}

* Means are not significant; DF: Degree of freedom; MS: Mean of squares.

Table ( 5 ): ANOVA for the means of the of linear dimensional changes (mm) of the Group I and Group IV.

\begin{tabular}{cccccc}
\hline \multirow{2}{*}{ S.O.V } & \multirow{2}{*}{ DF } & \multicolumn{5}{c}{ Linear dimensional changes of (mm) } \\
\cline { 3 - 6 } & & SS & MS & F & $* \mathbf{P} \leq \mathbf{0 . 0 1}$ \\
\hline *Tested groups & 1 & 0.25 & 0.25000 & 50.00 & 0.000 \\
Error & 14 & 0.07 & 0.00500 & & \\
Total & 15 & 0.32 & & & \\
\hline
\end{tabular}

*Means are highly significant different; DF: Degree of freedom; MS: Mean of squares. 
Table (6): Duncan Multiple Range test for the mean of the linear dimensional changes ( $\mathrm{mm}$ ) of the tested groups.

\begin{tabular}{cccc}
\hline \multirow{2}{*}{ Tested groups } & \multicolumn{3}{c}{ Linear dimensional changes (mm) } \\
\cline { 2 - 4 } & Number & Mean \pm SD & *Grouping \\
\hline Group I & 8 & $0.1 \pm 0.0756$ & $\mathrm{~A}$ \\
Group II & 8 & $0.18 \pm 0.1143$ & $\mathrm{~A}$ \\
Group III & 8 & $0.2 \pm 0.1414$ & $\mathrm{~A}$ \\
Group IV & 8 & $0.35 \pm 0.0655$ & $\mathrm{~B}$ \\
\hline
\end{tabular}

*Means with different letters are highly significantly different at $P \leq 0.01$, and the means with the same letter are not significantly different at $P \leq$ 0.05; SD: Standard deviation; Group I: specimens immersed in distilled water (control group); Group II: specimens immersed in (0.2 \%) clorhexidine solution; Group III: specimens immersed in $(0.05 \%)$ sodium hypochlorite solution; Group IV: specimens sterilized by microwave irradiation.

The dimensional changes in Group I related to that, the polymethyl methacrylate acrylic resins were hydrophilic, the absorption is undoubtedly due primarily to the polar properties of resin molecules. So acrylic resin have a tendency to absorb water, which causes dimensional change (12, 18-21). This result comes in agreement with the result of Karl etal ${ }^{(13)}$, in that during clinical use the acrylic resins that when immersed in saliva or soaked in denture cleansing solutions or water, resulting in absorption of water. The phenomena of sorption producing deleterious effects on the structure and function of the polymeric material. These effects may include volumetric changes such as swelling The swelling (expansion) of the resin is produced by water absorption forcing the macromolecules apart ${ }^{(18-20,22)}$.

The dimensional changes that result from sterilization by chemical solutions in Groups II and III come in agreement with the finding of Arthur etal ${ }^{(18)}$ and others ${ }^{(19,}$ ${ }^{20)}$ in that, regardless of specific chemistry, dental polymers tend to undergo adsorption of liquids. The polymer networks may absorb water and chemicals from the environment. In turn, the network may release components to its surroundings producing deleterious effects including dimensional instability.

A possible explanation of linear dimensional changes in Groups IV is the increasing water temperature, during microwave disinfection increased from $\left(21^{\circ} \mathrm{C} \pm 1\right)$ and reached $\left(71^{\circ} \mathrm{C}\right)$. This result come in agreement with the finding of Karl etal ${ }^{(13)}$, in that during microwave disinfection the materials are exposed to high temperature. Microwaves cause the water molecules to vibrate 2 to 3 billion times / second, thus producing friction that results in the heating of the water. And the high temperatures associated with the movements of molecules probably cause the water molecules to diffuse more rapidly into the polymer ${ }^{(6)}$. The uptake of water may cause swelling that affects the dimensions of the restoration and chemical changes such as oxidation and hydrolysis ${ }^{(18)}$. Also when heat-cured resin subjected to further heating, additional dimensional change was expected because of the release of the inherent stress established during the first curing ${ }^{(23)}$. But this result disagree with the finding of Burns etal ${ }^{(24)}$, in that sterilization by microwave irradiation produced no clinically significant influence on the dimensional stability of acrylic resins.

So sterilization method that produce low water sorption has been considered desirable for dimensional stability of dental prostheses ${ }^{(21)}$.

\section{CONCLUSSIONS}

The results proved that the sterilization by the microwave irradiation produce a significant effect on the dimensional stability of the heat-cured acrylic resin, while sterilization by chemical solution $(0.2 \%)$ clorhexidine solution and (0.05 \%) sodium hypochlorite solution, produce no significant difference.

\section{REFERENCES}

1. Pekka KV. Flexural properties of acrylic resin polymers reinforced with unidir- 
ectional and woven glass fibers. $J$ Prosthet Dent. 1999; 81: 318-326.

2. Richard VN. Introduction to Dental Materials. $2^{\mathrm{d}}$ ed. Mosby Co. Missouri, USA. 2002; Pp: 96-124.

3. James JL, Stephen MC and Dennis AR. Disinfection of denture base acrylic resin. J Prosthet Dent. 1999; 81: 202-6.

4. Karl KF, Frank DN, Dennis AR. Effectiveness of chlorine dioxide in disinfection on two soft denture liners. $J$ Prosthet Dent. 1998; 80: 723-29.

5. Tsun M ,Glen H, Glenn E. Effects of chemical disinfectants on surface characteristics and color of three fixed prosthodontic crown materials. $J$ Prosthet Dent. 1999; 82: 600-7.

6. Nara HC, Ana CP and Carlos EV. Effect of microwave sterilization and water storage on the Vickers hardness of acrylic resin denture teeth. J Prosthet Dent. 2005; 93: 483-7.

7. Renata CM, Blanca LT and Viviane MB. Effect of a denture cleanser on weight, surface roughness, and tensile bond strength of two resilient denture liners. $J$ Prosthet Dent. 2003; 89: 489-94.

8. Xavier L and Glen H. Accuracy of polyether and addition silicone after long-term immersion disinfection. J Prosthet Dent. 1997; 78: 245-49.

9. El-Ameer SS. The effect of long-term chlorhexidine disinfection on the staining of acrylic resin. Iraqi Dent J. 2000; 25: 145-156.

10. Abrer DJ. Post-placement care of complete and removable partial dentures. Dent Clin North Am. 1979; 23 (1): 143-150.

11. Faraj SA, Al-dabagi. The effect of denture cleaner on the surface roughness of denture base material. Iraqi Dent J. 2000; 25: 121-135.

12. Donna LD, Larry CB, Tracy AF. Microwave disinfection of denture base materials colonized with Candida albicans. J Prosthet Dent. 1999; 81: 207-14.

13. Ana LM, Larry CB, Aaron DP. Effect of microwave disinfection on the hardness and adhesion of two resilient liners. $J$ Prosthet Dent. 2005; 94: 183-89.
14. Ana LM ,Carlos EV, Eunice TG. Effect of a heat-treatment on the linear dimensional change of a hard chair side reline resin. $J$ Prosthet Dent. 2002; 88: 611-15.

15. Hassan NH. The effect of disinfectant solutions on the surface topography of acrylic denture base materials. MSc. Thesis. Collage of Dentistry. University of Mosul. 2001.

16. Phillip LJ, David RR, Robert KF. Dimensional change in complete dentures fabricated by injection molding and microwave processing. J Prosthet Dent. 2003; 89: 37-44.

17. Tomoyuki I, Noriyuki W, Masahiro O. Effects of polymerization shrinkage on the interfacial stress at resin-metal joint in denture-base: A non-linear FE stress analysis. Dent Mat. 2006; 22: 413-419.

18. Jack LF. Hygroscopic and hydrolytic effects in dental polymer networks. Dent Mat. 2006; 22: 211-222 .

19. Peter P and Ernst-Ulrich R. Residual methyl methacrylate monomer, water sorption, and water solubility of hypoallergenic denture base materials. $J$ Prosthet Dent. 2004; 92: 72-8.

20. Arthur S, Frederick C, John C. Color stability of provisional crown and fixed partial denture resins. $J$ Prosthet Dent. 2005; 93: 70-5.

21. Nur H, Gfilay U, Fatih Y. Color stability of denture base acrylic resins in three food colorants. J Prosthet Dent. 1999; 81: 37579.

22. Debby MS, Leo YY, Robert KF. Effect of processing method on the dimensional accuracy and water sorption of acrylic resin dentures. J Prosthet Dent. 1999; 81: 300-4.

23. Edmond HN, Chow TW, Robert KF. Linear dimensional change of heat-cured acrylic resin complete dentures after reline and rebase. J Prosthet Dent. 1998; 80: 238-45.

24. Burns D, Kazanoglu A, Moon P. Dimensional stability of acrylic resin materials after microwave sterilization. Int $J$ Prosthodont. 1990; 3: 489-93. 